\title{
Capital Investment Requirements for Greenhouse Gas Emissions Mitigation in Power Generation on Near term to Century Time Scales and Global to Regional Spatial Scales
}

\author{
Vaibhav Chaturvedi ${ }^{a, 1}$, Leon Clarke ${ }^{a}$, James Edmonds ${ }^{a}$, Katherine Calvin ${ }^{a}$, Page Kyle ${ }^{a}$ \\ a Joint Global Change Research Institute, 5825 University Research Court, Suite 3500, College Park, MD, \\ USA
}

\begin{abstract}
Our paper explores the implication of climate mitigation policy and electricity generation technology performance for capital investment demands by the electric power sector on near term to century time scales. We find that stabilizing GHG emissions will require additional investment in the electricity generation sector over and above investments that would be needed in the absence of climate policy, in the range of 15 to 29 Trillion US\$ (48-94\%) depending on the stringency of climate policy during the period 2015 to 2095 under default technology assumptions. This increase reflects the higher capital intensity of power systems that control emissions as well as increased electrification of the global economy. Limits on the penetration of nuclear and carbon capture and storage technology could increase costs substantially. Energy efficiency improvements can reduce the investment requirement by 18 to 24 Trillion USS (compared to default technology climate policy assumptions), depending on climate policy scenario. We also highlight the implications of different technology evolution scenarios for different regions. Under default technology set, the heaviest investments across scenarios in power generation were observed in the China, India, SE Asia and Africa regions with the latter three regions dominating in the second half of the $21^{\text {st }}$ century.

Keywords: Integrated assessment modeling; capital investment; electricity generation; energy scenarios; climate policy

JEL classification: Q400, Q470, Q480, O160
\end{abstract}

\footnotetext{
${ }^{1}$ Corresponding author; Present affiliation: Council on Energy, Environment and Water, Thapar House, 124 Janpath, New Delhi, India. E mail: vaibhav.chaturvedi@ceew.in. Tel: +91-11-40733353
} 


\section{Introduction}

Decarbonization of electricity production and electrification of end-use sectors has been identified as an important component of a cost-effective greenhouse gas (GHG) emissions mitigation strategy on both global [1], [2], [3], [4]and regional scales [5], [6], [7], [8], [9], [10], [11].

In the absence of climate policy, electricity production would be expected to remain dominated by fossil fuels in most of the regions of the world [1], [2], [3], [4]. For example, the rapidly growing economies of China and India have energy systems that are dominated by abundant and inexpensive coal. A climate policy on the other hand could fundamentally change the electricity production system around the world ${ }^{2}$.

Deploying an energy system consistent with deep emissions reductions raises several important implementation questions, not the least of which is: How much investment do we need in electricity production system? This question forms the central motivation for this paper.

Very few studies have analyzed capital investment requirements for electricity generation under alternative combinations of technology availability and climate mitigation policies [13], [14], [15], [16], [17], [18], [19], [20], [21], [22], [23]. Most of these studies focus on the near term. Appendix 1 presents a summary of some recent studies, most of which have focused on a time horizon of 2030 or closer.

In general the studies in Appendix 1 report an increase in the investment requirement for electricity generation sector for meeting emission mitigation objectives. However, there are two important gaps in the existing literature. First, the suite of scenarios examined is very limited in its scope. Many studies report one reference and one mitigation scenario across studies. There can be numerous future scenario pathways depending on different combination of technology and climate policy choices having varied implications for different regions and technologies. Second, the time horizon is generally limited to 2030-35 (the exceptions are [13], [22], [23]), so there is little information available about medium term (to 2050) and no information about investment requirements in the second half of the $21^{\text {st }}$ century.

A recent study by McCollum et al. [22] analyzes the investment requirement up to 2050 for the whole energy system transformation required for meeting a $2^{\circ} \mathrm{C}$ climate change target. This study reports investment results derived from model comparison exercise LIMITS for overall energy system, but also gives some information for electricity sector investments. In the overall, this study also reports an increase in required investment for total energy system as well as electricity sector for meeting emission mitigation objective. Renewable electricity sector would potentially require the largest increase in investments compared to Reference scenario, $150 \mathrm{Bn}$ US\$/yr for industrialized countries and $400 \mathrm{Bn}$ US\$/yr for developing countries average during 2010-50. Investment in nuclear energy varies across models due to varying underlying assumptions about the penetration of this technology, reflecting the

\footnotetext{
${ }^{2}$ It is interesting to note that model intercomparison exercises examining the long-term behavior of energy systems in the context of policies to limit climate change have shown that some models converge towards a common energy system across regions while other retain strong differences across regions over time [12], which will be reflected in electricity supply technology mix across regions.
} 
widely varying risk concerns across the world. The strength of this study lies in the comparison across models that have different analytical framework and hence arrive at different results and insights. Interestingly, one model- IMAGE, does not show any perceptible increase in supply side investment requirement under a stringent climate policy compared to the Reference scenario. This study does not explore the implications of alternative technology evolution pathways on future investment requirement, which is an important contribution of our study.

Another study that needs mention is Carraro et al. [23], which analyzes a Reference and a suite of four climate policy scenarios. The policy scenarios aim at four GHG concentration stabilization levels at 680, 560,500 and 460 ppmv $\mathrm{CO}_{2}$-eq level in 2100 . This research looks not only at power sector investment, but also total macroeconomic costs, investments in innovation, and revenues from carbon tax. This study shows that power sector investments under the 680 and 560 ppmv $\mathrm{CO}_{2}$-eq scenarios decrease by approximately 5\% between 2010 and 2050 relative to reference scenario. However, an increase of $3 \%$ and $10 \%$ respectively is observed under the 500 and 460 ppmv $\mathrm{CO}_{2}$-eq scenarios respectively. Energy efficiency improvements in the power sector, particularly in non-OECD countries, play an important role in reducing investment requirement under the less stringent climate policy scenarios. Interestingly, even though power sector investment requirement decreases under the 680 and 560 ppmv $\mathrm{CO}_{2}$-eq scenarios, the total macroeconomic costs are non-negative. This study is particularly valuable as it explores investment implications for a range of climate policy scenarios, something which the other literature largely lacks. As it is unclear as of now that which emission trajectory will the world move towards, the study gives a useful comparison of investments and costs across these different pathways. However, this study also does not explore implications of various technological pathways and scenarios in investment requirements, which is the research gap that we seek to contribute to.

The present study aims to fill these research gaps. Specifically we seek to examine the following questions:

1. Is additional capital investment required for electricity generation for meeting emission mitigation policy objectives?

2. What is the magnitude of additional investment requirement, if any, in the short, medium and long run under different technology and policy scenarios?

3. What are the reasons for increased or decreased capital investments?

4. What are the investment implications for different regions?, and

5. What are the investment implications of technology availability?

Our study highlights not just the total change in capital investments, but equally importantly, where those investments occur and which technologies receive them. The next section presents our method, scenario descriptions, and cost assumptions. Section 3 focuses on results and answers the five research questions outlined above. Finally, the conclusions of our research are presented in Section 4.

It should be noted that our results do not include investments in transmission and distribution, and focus only on investments in generation. The strength of our integrated assessment modeling framework is capturing the complex interactions between technology and climate policy scenarios for 
bringing out the investment implications. Our model includes a factor for T \& D losses, but not these costs as these cost do not critically affect technology choice and competition. Capital cost, operation costs, and endogenously determined fuel costs are included in the cost of competing electricity generation technologies. We have hence kept T \& D costs out of the scope of our analysis and focused on direct capital investments that are included in our analytical framework.

\section{Approach}

\subsection{Modeling framework}

We use Global Change Assessment Model (GCAM), a model of human and bio-geophysical Earth systems ${ }^{3}$, for understanding the evolution of electricity production system under various scenarios. GCAM an integrated assessment model with closely coupled energy, economic and land-use component. GCAM tracks the production, transformation and consumption of fossil fuels, renewables, and nuclear energy to meet the energy-service demands for three final-demand sectors- buildings, industry and transport, and operates from 2005 to 2095 in five year time steps. In GCAM, the world is divided into 14 geopolitical regions. Energy consumption and emissions of 16 greenhouse gases including carbon dioxide are tracked for these 14 regions. GCAM has been extensively used for global and regional energy and climate policy scenario analysis [24], [25], [26], [27], [28], [29], [30], [31], [32], [33], [34], [35].

As our paper focuses on investment for electricity generation, it should be noted here that final energy demand for various sectors is sensitive to energy prices. Energy prices are endogenous to the model. Further details about end use energy demand for different sectors in GCAM can be found in [28], [29], [30] and [34].

\subsection{Scenario description}

We analyze and compare a total of 20 scenarios which are combinations of different technology availability and performance assumptions in conjunction with two alternative degrees of climate policy stringency (Table 1$)^{4}$. We explore the implications of technology variations across policy scenarios. The Reference scenario is a No Policy scenario with default technology assumptions. As the future world can evolve in different ways which will have different investment implications, our technology variation scenarios explore this inherent uncertainty in future investment requirements. The same is true for the climate policy scenarios. The 20 scenarios test the sensitivity of our reference, no explicit greenhouse gas emissions mitigation policy scenario. That reference scenario is described in [31], which in turn is similar in nature to the reference scenario for Representative Concentration Pathway 4.5 [33].

\footnotetext{
${ }^{3}$ Refer http://wiki.umd.edu/gcam/index.php?title=Main Page for detailed GCAM documentation

${ }^{4}$ The scenario architecture is based on the Energy Modeling Forum 27 (EMF27) study protocol. Refer [31]
} 
We present results for 8 technology scenarios under No Climate Policy, 7 under a radiative forcing limit of $3.7 \mathrm{~W} / \mathrm{m}^{2}$ without overshoot, and 5 under a radiative forcing limit of $2.6 \mathrm{~W} / \mathrm{m}^{2}$ in the year 2095 with overshoot ${ }^{5}$ allowed. (Radiative forcing of $3.7 \mathrm{~W} / \mathrm{m}^{2}$ corresponds to a $550 \mathrm{ppm} \mathrm{CO}_{2}$-equivalent concentration and $2.6 \mathrm{~W} / \mathrm{m}^{2}$ corresponds to a $450 \mathrm{ppm} \mathrm{CO}_{2}$-equivalent concentration).

Some scenarios assume that nuclear and CCS technologies are available (ON) or unavailable (OFF), and potential for wind and solar is either assumed to be high (Adv) or low (Cons). Some scenarios assume higher energy efficiency improvements ( $A$ world with highly efficient end use technologies) while some assume a comparatively lower rate of improvements (Ref). Finally bioenergy consumption is endogenously calculated within GCAM without any constraints (Ref) ${ }^{6}$ or is constrained to 100 EJ (Low) including all sources of bioenergy, but not traditional biomass. Each climate policy scenario analyzes a suite of technology combinations described above. Refer [34] for quantitative assumptions of reference and advance solar and wind technology and higher end use efficiency(or low energy intensity) in GCAM.

Electricity production estimates under various scenarios have been converted to installed capacity using capacity factors (refer Table 3). The installed capacity (new vintage) of different electricity generation technologies have been multiplied with capital cost assumptions for arriving at total investment estimates for electricity generation for future under different scenarios. Detailed capital cost assumptions are presented in Table 2 . The investment costs presented in the paper are in real prices and are not discounted, and should not be used as a proxy for net present value ${ }^{7}$.

\subsection{Capital cost assumptions}

Assumptions about capital cost are critical as these shape our results of future investment pathways under various scenarios. Table 3 presents our assumptions about the cost pathways of different technologies. These are based on 2008 Annual Energy Outlook [37]. For all technologies, overnight capital cost decreases with time, though the rates of decrease are different across technologies.

\footnotetext{
${ }^{5}$ An overshoot scenario is one in which the eventual limit is exceeded for some period prior to the evaluation period. For example, in an overshoot scenario a target of $2.6 \mathrm{Wm}^{-2}$ in the year 2095 might be exceeded in periods prior to 2100 as long as it radiative forcing was returned to $2.6 \mathrm{Wm}^{-2}$ in the target year, 2095.

${ }^{6}$ In the unbounded cases bioenergy production is determined endogenously in the GCAM model. Bioenergy crops must compete for land with other crops and alternative land uses on the basis of expected profitability. In climate policy scenarios GCAM assumes that terrestrial carbon is valued equally with fossil fuel and industrial carbon, so that economic incentives are provided for afforestation. Bioenergy market penetration and afforestation are limited by inelastic food demands. See [25] for further discussion.

${ }^{7}$ Aside from the discount rate, there are three uncertainties highlighted by the anonymous reviewer that we have not analyzed: the future energy prices, future energy demand levels, and GDP growth. The reviewer is correct in pointing out that all of these will have consequences for the level of electricity investment far into the future, and also that they are not among the variables that we have explicitly addressed in this study. Because future energy prices and demand levels in GCAM are endogenous, they are influenced by the variables that we have addressed in this study: the stringency of climate change mitigation efforts, and the costs and availabilities of low-emissions technology options in the power sector. In this study we have not addressed socioeconomic uncertainties (e.g., population, GDP growth, consumer preferences), nor have we assessed uncertainties related to resource availabilities and extraction costs, which will also be important for future energy prices and demand levels. However, any scenario-based analysis has to confront the trade-off between completeness and complexity; in our study, we have not set out to provide bounding ranges of future electric sector investment, but rather to assess the impact of climate change mitigation efforts on that level of investment for a range of future outcomes of electricity generation technologies.
} 
Our capital costs assumptions for most technologies are from the 2008 Annual Energy Outlook [37], because GCAM's calibration year is 2005. Since that time, the real costs of power technologies have changed, as they may do in the future as well. Because our focus is on the long term, we don't update our costs to capture year-to-year market fluctuations, as one would see in comparing the assumptions to the Annual Energy Outlook in the past 5 years. Appendix 3 presents comparison of the 2013 edition [45] to the 2008 edition, and the inflation-adjusted price changes are uniformly positive, except for solar $\mathrm{PV}$, and for coal and nuclear are in the $70 \%-100 \%$ range.

Though we are assuming fixed exogenous cost pathways for all technologies, it is important to highlight here that there is a range of uncertainty around these numbers. 2012 Annual Energy Outlook [46] gives a range around the total system levelized cost of different technologies for 2017 , due to regional variations in labor markets and the cost and availability of resources. Though levelized costs includes operation and maintenance cost also, we can use this information assuming that uncertainty in total system levelized cost is the similar to the uncertainty in the levelized capital cost. Assuming this, figure 1 presents our capital cost assumptions for 2020 and the uncertainty range around it. In this paper, we only test the sensitivity of scenarios to variations in technology and climate policy, and not the sensitivity of scenarios to uncertainty around capital cost. Our assumptions of capital cost are same across all the scenarios.

As is evident from the figure, there is significant variation in the cost of solar technologies, $-25 \%$ to $+60 \%$. For wind technology this variation is $-20 \%$ to $+17 \%$, for biomass technologies the variation is $15 \%$ to $+18 \%$ and for advance nuclear technology the variation is $-4 \%$ to $+7 \%$. For all fossil technologies including CCS, generally speaking the range is between $-10 \%$ to $+20 \%$. We do expect this uncertainty to remain with our assumptions about the future capital cost pathways as well, though uncertainty range would decrease as technologies mature. Readers should keep this variability in mind while interpreting our results.

\section{Results and Discussions}

\subsection{Electricity generation under reference and policy scenarios}

There are two important observations regarding global electricity generation. First, electricity generation increases significantly across the century even under the No Policy_Default, by more than three times between 2005 and 2050, and further by 1.6 times up to 2095. Second, in the long run electricity generation is higher under the climate policy scenarios. Generation in the 3.7_Default scenario is higher by 20 percent and in the 2.6_Default scenario by 50 percent compared to electricity generation under No Policy_Default scenario in 2095. Figure 2 also shows the range of electricity generation across technology scenarios.

Two of the eight 'No Policy' scenarios set the lower end of this range of the electricity generation-No Policy_Renew and No Policy_LowEl. These two scenarios at the low end assume high end use technology energy efficiency in the overall economy and hence total electricity generation in these 
scenarios is 15\% lower in 2050 and 33\% lower in 2095 in compared to all other scenarios. In terms of investment, increasing electricity generation will directly imply increased investment requirement, which we will discuss in detail in the following sections.

In terms of share of fuels and technologies, fossil fuels dominate the No Policy_Default electricity generation with $75 \%$ share in 2050 which decreases to $62 \%$ in 2095 due to increasing share of nuclear ( $22 \%$ in 2095 ) and solar plus wind (11\% in 2095). The dominant technology for electricity generation under the climate policy scenarios with default technology assumptions is nuclear technology with share of $46 \%$ and $50 \%$ in 2095 in the 3.7_Default and 2.6_Default scenarios respectively. For these two scenarios respectively, renewable's share increases marginally relative to No Policy_Default and ranges from $13 \%$ to $17 \%$ in 2095 . The rest is supplied by fossil and biomass CCS technologies.

Under the No Policy_Default tech scenario, installed capacity increases from more than 3200 Giga Watts (GW) in 2005 to $10400 \mathrm{GW}$ in 2050 and $16100 \mathrm{GW}$ in 2095. The installed capacity under the climate policy default tech scenarios is higher by $22 \%$ and $57 \%$ in 2095 under the 3.7_Default and 2.6_Default scenarios respectively compared to the No Policy_Default scenario.

The increase in installed capacity also reflects the shift of electricity mix towards other fuel sources. In the No Policy_Default scenario in 2095, the share of fossil energy in capacity mix is $66 \%$ with zero share of CCS, nuclear is $16 \%$ and solar and wind together are 18\%. Under the 2.6_Default scenario in 2095, fossil has only $17 \%$ share and all is with CCS, nuclear energy takes $36 \%$ share, wind and solar together corner $34 \%$ share, and biomass with CCS has $13 \%$ share. Corresponding numbers for the 3.7_Default scenario in 2095 are $21 \%$ fossil with CCS, 35\% nuclear, $11 \%$ biomass with CCS, and $30 \%$ for wind and solar together.

Capacity mix is altered significantly under technology variants of policy scenarios, which affects the investment requirement for electricity generation (Refer Appendix 2). e.g. under the no CCS scenarios, the combined share of wind and solar increases to $43 \%$ under the 3.7 NoCCS scenario and $50 \%$ under the 2.6_NoCCS scenario in 2095, while it is ranges between 28-31\% in 2095 under the low renewable technology variants of the respective policy scenarios. Refer Table 3 for information on capacity factors for different technologies.

\subsection{Capital investment requirement for electricity generation}

\subsubsection{Investment requirement under reference scenario}

Technology availability assumptions associated with the No Policy_Default scenario are given in Table 1. Other 'No Policy' scenarios form an envelope of technology sensitivities around this core reference scenario. Driven by economic and population growth, electricity generation investment increases substantially in the long term compared to the near term under the No Policy_Default scenario. Under the No Policy_Default scenario, the investment requirement for electricity generation to meet global electricity demand increases from $239 \times 10^{9}$ US\$/yr for 2015-30 to $345 \times 10^{9}$ US\$/yr for 2031-50 period 
and $443 \times 10^{9}$ US\$/yr for 2050-95 period (Figure 3, prices are in 2007 US\$ unless specified otherwise). As a percentage of GDP, investment is .37\% in the 2020 to 2025 period, which declines to $.30 \%$ between 2050 and 2055 and to $0.13 \%$ in the $2090-95^{8}$ timeframe. Investment in electricity for fossil and renewable energy were $237 \mathrm{Bn}$ US\$ and $223 \mathrm{Bn}$ US\$ respectively in 2011 [19], totaling to .65\% of global GDP.

\subsubsection{Additional investment requirement under climate policy scenarios}

Investment demands by the power sector are higher in the climate policy scenarios we have examined than under the No Policy scenarios. The difference is marginal in the short run, but significant in the long run (Figure 4). As overshoot is allowed under the 2.6 scenarios, a sharp decline in emissions is observed in the latter part of the century to meet stringent stabilization targets, implying that under this scenario a large part of investment would be in the second half of the $21^{\text {st }}$ century. Under the 3.7_Default scenario, average annual global investment in electricity generation during the period 2015 to 2030 is $254 \times 10^{9}$ US\$/yr, which increases to $551 \times 10^{9} \mathrm{US} \$ / \mathrm{yr}$ for the period 2030 to 2050 , and $670 \times 10^{9}$ US\$/yr for the period 2050 to 2095. The requirements under the 2.6_Default scenario for the respective time periods are $\$ 300, \$ 674$ and $\$ 910 \times 10^{9}$ US\$/yr respectively.

The stringency of stabilization policy is an important determinant of the investment requirement, irrespective of the technology scenario. Other things equal, more stringent policies drive more rapid deployment of capital-intensive power generation infrastructure (discussed in Section 3.3). The cumulative additional investment requirement, relative to the No Policy_Default scenario, between 2015 and 2095 is $\$ 15$ and $\$ 29$ Trillion US\$ for the 3.7_Default and 2.6_Default scenarios respectively. In terms of average across technology scenarios, this increase in investment requirement is $\$ 17$ and $\$ 33$ Trillion US\$ for the $3.7 \mathrm{~W} / \mathrm{m}^{2}$ and $2.6 \mathrm{~W} / \mathrm{m}^{2}$ overshoot stabilization scenarios respectively. Thus the additional capital investment required for emissions mitigation is almost doubled under the more stringent scenario. GCAM results included in McCollum et al. [22] show increase in generation investment by $67 \%$ between 2020 and 2050 under the 2.6_default scenario. This is similar to our results for the period 2020-50, and as our study looks at a longer horizon, we find that investment requirement increases significantly post 2050 as abating greenhouse gas emissions becomes even costlier with time and as the lower cost opportunities are already tapped prior to 2050.

We note that additional capital investment potentially would be required for transmission and distribution in a low-carbon world, in our study we focus only on investments for generation. In fact, McCollum et al. [22] show in their model comparison study that the investment required between 201050 in transmission, distribution and storage is $50-100 \%$ of the investment required for building power

\footnotetext{
${ }^{8}$ The small dip between years 2050 and 2065 is due to lower capacity additions. In these years, older vintages of generation capacity are sufficient to meet a larger share of electricity demand compared to other years when larger installation of new capital is required. Consequently the requirement for building new power plants declines during this period lowering the investment requirement. Similar decline is observed in the century end as well.
} 
generation capacity for the Reference scenario. T \& D investment also increases under climate policy, but not by the same percentage as the increase in electricity generation investment for meeting climate policy targets.

Under the more stringent climate policy, $2.6 \mathrm{Wm}^{-2}$, the range of investment requirement across technology scenarios is greater than that under the $3.7 \mathrm{Wm}^{-2}$ scenarios. This range is relatively small across the different technology availability and performance assumptions of the 'No Policy' scenarios (Figure 5).

The right hand side of Figure 5 compares the range of power generation investment requirements relative to Gross World Product across time. We note that under the 'No Policy' scenarios, investment as a share of GDP declines irrespective of the technology scenario. The average share of GDP across technology scenarios declines from .38\% of GDP during 2020 to 2025 to .12\% of GDP during 2090 to 2095. Under the $3.7 \mathrm{~W} / \mathrm{m}^{2}$ stabilization policy, the average share across technology scenarios increases to a peak at $0.51 \%$ of GDP between 2045 and 2055 and then declines to $0.21 \%$ by the 2090 to 2095 period.

Looking at the range of investment as a share of GDP, we observe a shift in the peak of investment when moving from the 3.7 to 2.6 stabilization scenarios. This shift of peak to an earlier time period highlights the importance of near-term investment actions for achieving stringent climate policy goals. This peak in the 2.6 scenario is observed for the no nuclear technology case.

As exhibited in Appendix 1, most of the estimates of power sector investment demands in the literature pertain to a time horizon of 2030 to 2035 (see e.g. [15], [18], [20], [21]). Figure 6, shows that our estimates tend to confirm the existing near-term literature. That literature also suggests that the investment requirement for electricity generation will increase under climate policy scenarios relative to a no climate policy scenario, unless there are significant investments in energy efficiency measures which can reduce energy demand substantially, a finding also consistent with this study.

Our results can be compared more closely with McCollum et al. [22] and Carraro et al. [23], as both studies have used similar energy models as ours. Carraro et al. [23] gives total investment numbers, that can be directly compared with our results (refer Appendix 1 and Figure 6). Our conclusions are at wide variation with Carraro et al., which concludes that a 460 ppmv CO2e scenario leads to only a $10 \%$ increase in investment requirement between 2010-50 compared to the Reference case, while our estimates show a $70 \%$ increase in investment requirement during this period due to a stringent climate policy. McCollum on the other hand give ranges for different technology groups (fossil, renewable and nuclear) which cannot be added directly to derive total investment numbers. Our default scenario investment estimates for fossil energy and nuclear energy (refer Figure 11 and Appendix 1) for both Reference and $2.6 \mathrm{~W} / \mathrm{m} 2$ scenario are well within the range specified by McCollum et al. However, investment for renewable technologies are much lower in our case- $49 \mathrm{Bn}$ US\$/year between 2015-50 under the Reference scenario and $105 \mathrm{Bn}$ US\$/year under the $2.6 \mathrm{~W} / \mathrm{m} 2$ scenario. This is compared to 146-256 BnUS\$/year under Reference and 212-729 BnUS\$/year under the 450 ppmv CO2e scenario for the McCollum study ([22], refer Appendix 1). Difference in our results and results of McCollum et al. [22] 
and Carraro et al. [23] can be due to many differences in the modeling approaches and assumptions. For detailed insights on why model results on energy and emission pathways can potentially vary by a wide margin, please refer Clarke et al. [12].

\subsubsection{Role of key technologies in determining mitigation cost}

Technology performance and availability are important determinants of investment capital demands. We find, for example that if carbon dioxide capture and storage(CCS) technology is unavailable, that investment requirements rise steeply relative to other technology scenarios before 2050 under both the $2.6 \mathrm{Wm}^{-2}$ and $3.7 \mathrm{Wm}^{-2}$ emissions limitation policies(Figure 7). After 2050, the absence of CCS technology results in the highest demand for capital investment resources under the $3.7 \mathrm{~W} / \mathrm{m}^{2}$ scenarios, though not in $2.6 \mathrm{Wm}^{-2}$ scenarios. The reasons for this increase in capital cost are discussed in section 3.3.

Under the $2.6 \mathrm{Wm}^{-2}$ policy increases in investment capital requirements are greatest in the absence of the ability to deploy nuclear power-increasing by more than 54 Trillion US\$ between 2021-2095 relative to the reference no policy scenario, almost $90 \%$ higher than the additional cost under the default tech 2.6 scenario.

Energy efficiency improvements can also play an important role in reducing investment cost. End-use energy efficiency improvements reduce the demand for power while enhancing the provision of energy service and thereby reduce the need for new investments in power production. The hypothetical improvements explored in this study reduced the cumulative investment requirement by 9.4 Trillion US\$ between 2020 and 2095 under the no policy scenario, as compared to default technology scenario. Interestingly, if energy efficiency improves at a rate as assumed in this scenario, there would be no additional electricity investment required to meet the 3.7 stabilization level. The cost of meeting the 2.6 stabilization level will also decrease by 23 Trillion US\$ across the century, a $40 \%$ reduction in requirement relative to the 2.6_Default scenario. To the extent that end-use energy efficiency is deployed through end-use capital plant and equipment, there will be further effects on aggregate investment. Such changes are beyond the scope of this study, however.

\subsection{What are the reasons for additional investment requirements?}

Three forces operate to increase investment requirements for electricity generation under the climate policy scenarios relative to the no policy scenario. We refer to these as the electrification, capacity utilization and capital intensity effects.

The Electrification effect reflects the fact that other things equal, more (less) investment is required as the total amount of electricity increases (decreases). A climate policy induces a shift toward electricity 
(depending on carbon prices and available technology set) and away from the direct use of fossil fuels in the economy because power generation can substitute non-emitting technologies for emitting technologies at costs smaller than the carbon price. Of course, energy conservation technologies are also advantaged by a carbon tax, and the total demand for electricity can either rise or fall. To the extent that more (less) power is demanded in aggregate, the demand for investment capital for new power generation capacity will be increased (decreased).

Capacity utilization is measured by the ratio of total installed capacity to total power generation. Renewable energy technologies that depend on resources with variable availability and/or conventional fossil fuel power plants used for peaking have a lower capacity factor compared to conventional baseload fossil or nuclear power plants. A shift toward (away from) power generation technologies with lower capacity utilization will increase (decrease) total investment in power generation capacity.

Capital intensity is the ratio of capital investment per unit of installed capacity. Technologies that are more capital intensive directly increase the demand for investment resources without increasing capacity. On the other hand, more capital intensive investments conserve on other scarce resources, usually fuel. Solar power, for example, has higher capital requirements per unit of installed capacity than a natural gas turbine, yet it incurs no fuel costs in its operation. Technologies with similar capacity factors can also have different initial capitalization costs, for example a natural gas plant with CCS technology has the same capacity factor as a non-CCS natural gas plant, but a higher initial capital cost.

We attribute the contribution of each of the three forces discussed above using the Investment Decomposition Identity formulation, similar to the Kaya identity formulation [47]:

$$
\begin{aligned}
& \mathrm{I}=\mathrm{K} * \mathrm{C} * \mathrm{E} \text {, where } \\
& \mathrm{I}=\text { Investment [US\$], } \\
& \mathrm{K}=\text { Investment }[\mathrm{US} \$] / \text { Generation capacity }[\mathrm{GW}], \\
& \mathrm{C}=\text { Generation capacity }[\mathrm{GW}] / \text { Electricity generation }[\mathrm{EJ}] \text {, and } \\
& \mathrm{E}=\text { Electricity generation }[\mathrm{EJ}]
\end{aligned}
$$

Therefore, $\ln (\mathrm{I})=\ln (\mathrm{K})+\ln (\mathrm{C})+\ln (\mathrm{E})$ and

$$
\Delta \ln (\mathrm{I})=\Delta \ln (\mathrm{K})+\Delta \ln (\mathrm{C})+\Delta \ln (\mathrm{E})
$$

The first right-hand term in the equation above is the capital intensity effect, the second term as the capacity utilization effect, and the third term as the electrification effect.

Figure 8 displays results from the Decomposition Identity calculations normalized to reference scenario investments for two emissions mitigation scenarios, the $3.7 \mathrm{Wm}^{-2}$ (left-hand panel) and $2.6 \mathrm{Wm}^{-2}$ (righthand panel) climate forcing limits. The change in average investment per unit installed capacity, $\Delta \ln (\mathbf{K})$, the Capital intensity effect, has the largest effect before 2050 influencing the increase in aggregate capital investment in both mitigation scenarios. Increasing capital intensity is responsible for more than 
$70 \%$ increase in the investment requirement under climate policy scenarios relative to the stabilization level during this time period.

In later years of the climate mitigation policy, the Electrification effect, $\Delta \ln (E)$, plays a more significant role, under both the climate forcing scenarios, though the effect is actually negative in early years in both policy regimes.

Capacity utilization effect, $\Delta \ln (\mathbf{C})$, is generally positive, but it explains relatively little of the increase in aggregate investment under either emissions mitigation regime in the default technology scenarios ${ }^{9}$. A slightly negative capacity utilization effect is observed under the 3.7_default scenario in the latter half of the century, which implies that capacity installed per unit of electricity produced is lesser compared to that under the No Policy_Default scenario. This is only possible with higher share of technologies that have higher capacity factors compared to coal and other fossil fuels, which are the dominant fuel source under the No Policy_Default scenario. This scenario hence sees higher share of nuclear in the latter half of the century (please refer Table 3 for details on technology capacity factors), which reduces the effect of additional capacity installations on total investments. It should be highlighted here that the capacity utilization effect is larger under high renewable scenario and scenario without nuclear energy. Particularly under the 3.7_NoNuc scenario and 3.7_Renew scenario, change in installed capacity contributes by $20-31 \%$ in the total investment increase from 2065 and onwards (Refer Appendix 4 and 5). For the 2.6_NoNuc scenario, the contribution is between 19-23\% for 2065 and onwards. Both these technology variation scenarios have high share of renewable, hence the capacity utilization effect gains importance.

The decomposition analysis has some important insights relevant for policy. We show that the capital intensity effect is the dominant effect. Achieving stabilization goals implies valuing the negative externality associated with greenhouse gas emissions, modeled as carbon price in our analysis. Low carbon technologies, being more costly relative to conventional fossil technologies, are not cost competitive under the no climate policy scenarios. However valuing carbon tilts the balance in favor of these costlier technologies. Hence even if there is zero electrification effect and capacity utilization effect, higher share of low carbon technologies will increase the investment requirement significantly. It is important hence to invest in research that can decrease the cost of these low carbon technologies either through increasing transformation efficiencies or decreasing material and installation costs.

One important strategy for meeting climate goals that is being debated is the shift towards electricity away from conventional fuels for meeting the end use service demands, as it is easy to decarbonize the electricity sector than decarbonizing end uses directly. Increase in electricity production is hence an important contributor to total investment. However moving away from other fuels implies decrease in

\footnotetext{
${ }^{9}$ The pure Capacity utilization effect plays a relatively minor role on average, even though many renewable power technologies have a low capacity factor, and CCS technologies have an energy penalty associated with their use. While the pure capacity utilization effect explains only a small part of the overall increase in investment demand, some of the effects of higher resource variability play out in higher capital requirements per unit of power generated in the form of backup capacity investments.
} 
the cost of these, e.g. lower investment in refining capacity for oil if transportation and industry moves away from oil towards electricity. Though investments in the broader energy system is outside the scope of our analysis, we do highlight that it is possible that the increase in investment due to the electrification effect is potentially largely compensated by decrease in investment in other energy sectors. In the overall, electrification of end use services does appear to be a cost minimizing strategy for meeting climate goals.

The effect of capacity utilization effect is largely negligible. However, here we should highlight that apart from nuclear, no low carbon technology has a higher capacity factor compared to conventional fuels. Strategies like storage increase the capacity factor at an additional cost, which is most important for optimum usage of natural energy resources, particularly renewable technologies. It hence becomes a tradeoff between additional cost versus additional increase in capacity attained with this cost. Storage and other technologies that can increase the capacity factor can ultimately bring down the overall electricity system cost, and hence are very important from the perspective of long term evolution of electricity systems.

\subsection{Regional distribution for investment}

The important contribution of the paper is not only estimates of future capital investments, but more importantly where these investments occur and in what technologies. In terms of regional distribution of investment under the no climate policy scenario, the largest single-region share of investment funds allocated to power generation is deployed in China in the period up to 2050, and that fraction declines in the future as the Chinese economy matures and other developing regions' demands for electricity grow. By 2050, India is another major investment destination and after 2050 India, SE Asia and Africa become important investment foci for electricity generation and together with China these regions account for $60-70 \%$ of global investments in 2095.

Two important points need to be mentioned for regional investment under climate policy scenarios. First, trajectories of investment depend on the mitigation potential of different regions. For example, under No Policy_Default scenario, there is a significant increase in fossil based electricity generation in China across the century. Consequently, China becomes an important region from the perspective of emission reduction efforts as well which is highlighted in the increase in investment in this region in low carbon electricity generation technologies.

Second, and most importantly, evolution trajectory of different technologies critically affect the share investment across different regions as well as that across time within a given region. This can be best illustrated in the case of India, where its share of global investment ranges from 13\% (3.7_NoCCS sc) to $25 \%$ (3.7_NoNuc sc) in 2095, depending on the technology scenario. Non availability of nuclear technology under the 3.7 scenarios leads to shift in investment patterns across the world, with more solar power generation in India and hence increases the share of India in global investment in 2095 to $25 \%$ (up from $15 \%$ under the default tech scenario). Similar variations, though comparably lower in magnitude are observed across regions under different technology scenarios. The choice of abatement 
region in GCAM depends on the criteria of least cost with cost being dependent on global technology evolution, and any given region's technology resources and mitigation potential. Changes in technology scenarios can hence have critical implications for individual regions.

Some important points need to be highlighted regarding ratio of investment requirement to GDP under the No Policy_Default tech scenario. First, it is interesting to note that for any region, excluding Africa, investment as a ratio of GDP either stays at the same level or declines in the future relative to period 2016-2020. Second, highest ratio of investment to GDP is for India in the near term and Africa in the long term.

Under the climate policy scenarios, all the regions invest a higher ratio of their GDP in electricity generation. Under the 2.6_Default scenario, higher increase relative to No Policy_Default scenario investment is observed for China before 2041-45. Post this period, India sees highest relative increase which goes up to four times for the period 2056-60. Finally after 2065, highest relative increase is observed for Africa which goes up by 2.6 times in 2076-80. Across scenarios, Africa still invests highest share of its GDP after 2045 compared to any other region.

\subsection{Investments by electricity generation technologies}

The importance of the evolution of different technologies for investment requirement cannot be over emphasized. In section 3.2.3, we analyzed the implications of technology availability on the investment requirements, i.e. variation of technology portfolio around the default technology set. In this section, we focus on investment requirement for different technology groups under the default technology scenarios. The composition of the investment portfolio over time and across policy assumptions is shown in Figure11.

Under our No Policy_Default scenario, investment in fossil based electricity generation remains high (69\%) before 2030 declining to $53 \%$ by 2095 (Figure 11). The share of investment drops dramatically in the climate policy scenarios.

The share of fossil power generation investment with CCS (and not absolute penetration) in the long run actually decreases with the stringency of policy. This reflects the fact that CCS technology does not capture $100 \%$ of carbon emissions. Under more stringent policy regimes and associated high carbon taxes those emissions shift the economic advantage to investments with zero or negative (bioenergy with CCS, BECCS) direct emissions. The same effect is observed over time under an individual emissions mitigation scenario because the carbon price rises with time. Another important possible reason is that CCS technology is competitive early on, and with time there is saturation in the penetration of CCS, with marginal investment in the electricity sector shifting to other technologies. Thus, investments in CCS technology are higher before 2050 under both the climate policy scenarios, after which its share declines. 
The share of investment in nuclear technology increases under the climate policy scenarios after 2030 as third-generation nuclear technology is assumed to be more efficient and cheaper than present technology.

Solar technology is also exogenously assumed to improve over time and benefits from climate policy. It takes on an increasingly important role in the mitigation portfolio particularly after 2050.

Finally, as shown in Figure 11, the technology investment portfolio under both climate policy cases is very different in 2050 compared to 2095 . The 2050 portfolio is dominated by CCS and nuclear technologies, while the 2095 portfolio is dominated by renewable power generation technologies.

As highlighted in section 3.2.3, technology variations will imply different distribution of investment requirement across technology groups. Under the no CCS scenarios, most of the investment shifts to nuclear technology. Under the no nuclear technology, some investment does shift towards CCS technology in the near term, but most of the investment shifts towards solar and wind technologies in the long run.

\section{Summing Up}

In this paper we explored the implication of greenhouse gas emissions mitigation policies on capital investment requirements for power production on near term to century time scales at global to regional spatial scales and under alternative technology performance and availability assumptions. It should be noted here that we have looked only at the capital investment requirement for electricity generation (excluding transmission and distribution), which increases under climate policy, and not the total energy system investment which might even decline as the total energy use declines under the climate policy scenario. We highlight that not only total change in investment is important, but it is equally important to highlight the regions and technologies where these investments undertaken.

We employed the GCAM integrated assessment model for examining a suite of 20 scenarios. GCAM was employed to examine a reference, no climate policy scenario and two alternative greenhouse gas emissions mitigation scenarios defined for EMF27, one limiting radiative forcing to $3.7 \mathrm{Wm}^{-2}$ (not to exceed), and another limiting radiative forcing to $2.6 \mathrm{Wm}^{-2}$ allowing overshoot prior to 2095 . That protocol also considered two alternative technology availability and performance states for five energy and power technologies: end-use energy efficiency, CCS, nuclear power, wind and solar power, and bioenergy.

It should be mentioned here that GDP growth and energy demand forecast vary widely across studies. Our study is in no way an attempt to give an all encompassing range of investment requirement for electricity generation. Our attempt is to highlight the implications of climate policy as well as technological uncertainty for electricity investments, something that can be done while assuming a fixed level of GDP growth. Sensitivity analysis around GDP growth assumption will provide more insights in the question of investment requirements and can be explored in future research. 
We note that there is a range of uncertainty underlying our capital cost assumptions, which at least in the near term is $-25 \%$ to $+60 \%$ for the solar technologies, -20 to $+20 \%$ for fossil, CCS and wind technologies, and $-4 \%$ to $7 \%$ for nuclear technologies. This implies that our estimates for scenarios having large share of solar energy are more uncertain compared to other scenarios, especially the ones having a large share of nuclear technology. This also means more uncertainty for regions which see a higher deployment of solar technology in our estimates. However, our estimates should provide a reasonable benchmark of investment requirements under different technology and policy scenarios for both the near term and the long term. Testing sensitivities around our capital cost assumptions can potentially provide important additional insights.

We begin by noting that even under reference, no climate policy scenarios investment requirement for electricity generation increases significantly over the $21^{\text {st }}$ century. Global investment requirement roughly double between 2015 and 2095 fueled by global population and income growth. Interestingly all the six technology scenarios (after excluding high end use energy efficiency scenarios) lead to similar investment patterns under the reference scenario. Investments in the high energy efficiency scenarios are smaller by $30 \%$ under no policy case and $40 \%$ in both the policy cases. This is mainly due to significant reduction in electricity consumption under the high end use efficiency scenarios. The cost reductions may, to some extent, be compensated by increased investment in the end use side for achieving higher levels of energy efficiency across end use sectors.

Electricity generation increases under climate policy scenarios as many end use demands move towards electricity, which affects investment requirements. However this would also imply that there would be decrease in other energy system investment. Whether the increase in investment for electricity generation will be compensated by commensurate decrease in other energy system investment would required a much wider analysis which is outside the scope of the current study. However, decrease in other investment would at least to some extent compensate for the increase in investment required for additional electricity generation as shown in our estimates.

Limiting greenhouse gas emissions lead to substantial additional investments compared to the No Climate Policy scenarios, in the medium as well as long run. The largest force shaping the increased demand for capital investment in the long run was the higher capital intensity of emissions mitigation power generation technologies compared to fossil fuel generation technologies, which were tend to be more fuel-intensive.

The stringency of climate policy, as well the evolution and availability of technologies is an important determinant of this investment requirement. Under default technology assumptions, the average cumulative investment requirement during 2020 to 2095 increased by 48\% (15 Trillion US\$) under the $3.7 \mathrm{~W} / \mathrm{m}^{2}$ scenario and by $94 \%$ ( 29 Trillion US\$) under the stabilization target of $2.6 \mathrm{~W} / \mathrm{m}^{2}$ with overshoot.

Technology availability and performance substantially affected aggregate capital investment demands for power generation. Energy efficiency improvements reduced additional cumulative investment requirement by 18 Trillion US\$ (in 2007 prices) under $3.7 \mathrm{Wm}^{-2}$ scenario and by 24 Trillion US\$ (in 2007 
prices) under $2.6 \mathrm{Wm}^{-2}$ scenario compared to the default tech scenarios across the century. In contrast, scenarios in which technologies were either degraded or unavailable, added to overall capital investment demands.

Finally, there was also substantial regional variation in the demands for capital investment for power generation facilities. China, India, SE Asia and Africa will be the main destinations for electricity generation investments. Most of the future population and economic growth is concentrated in these regions, which translates into more rapid increases in demands for energy and power. For India and China, the abundance and low cost of coal imply substantial emissions mitigation potential in the power sector. We also noted that while capital investment demands exerted a relatively modest claim on global Gross World Product and regional GDPs.

Our study has some key policy insights. Energy efficiency should be emphasized as an important area of intervention that has potential of significantly reducing the investments required on the energy supply side. Studies on the cost of energy efficiency options are limited in numbers as well as in terms of geographical areas covered. More information on the cost of different energy efficiency enhancement measures across sectors as well as geographical regions will help researchers and policy makers in making optimal choices. An important policy information need is related to uncertainty around cost and potential of renewable technologies, particularly solar energy. A better sense of future cost trajectory will be useful in aligning investment portfolios. Finally, absence of any key low carbon technology will result in sharp increase in the cost of meeting mitigation targets. From the perspective of cost effectiveness hence all technologies should be included in the emission mitigation portfolio to meet global climate targets with minimum investment requirement.

\section{Acknowledgments}

The authors are grateful for research support provided by the Global Technology Strategy Program. The authors are grateful to the U.S. Department of Energy's Office of Science for financial support for the development of the Global Change Assessment Model, which was used in this paper. This research used Evergreen computing resources at the Pacific Northwest National Laboratory's Joint Global Change Research Institute at the University of Maryland in College Park, which is supported by the Integrated Assessment Research Program in the Office of Science of the U.S. Department of Energy under Contract No. DE-AC05-76RL01830. The views and opinions expressed in this paper are those of the authors alone.

\section{References}

[1] Edmonds JA, Wise MA, Dooley JJ, Kim SH, Smith SJ, Runci PJ, Clarke LE, Malone EL, Stokes GM. 2007. Global Energy Technology Strategy: Addressing Climate Change. Phase 2 findings from an international public-private sponsored research program. Battelle Memorial Institute, College Park, MD, USA 
[2] IPCC. 2007. Fourth Assessment Report. Intergovernmental Panel on Climate Change

[3] Ang BW, Zhou P, Tay LP. 2011. Potential for reducing global carbon emissions from electricity production- A benchmarking exercise. Energy Policy 39, 2482-2489

[4] IEA. 2012. Energy Technology Perspectives. International Energy Agency, Paris, France

[5] Odenberegr M, Unger T, Johnsson F. 2009. Pathways for North European electricity supply. Energy Policy 37, 1660-1677

[6] Carley, S. 2011. Decarbonization of the US electricity sector: Are state energy policy portfolios the solution. Energy Economics 33, 1004-1023

[7] Lanz B and Rausch S. 2011. General equilibrium, electricity generation technologies and the cost of carbon abatement: A structural sensitivity analysis. Energy Economics 33, 1035-1047

[8] Chen Q, Kang C, Xia Q, Guan D. 2011. Preliminary exploration on low-carbon technology roadmap of China's power sector. Energy 36, 1500-1512

[9] Pappas C, Karakosta C, Marinakis V, Psarras J. 2012. A comparison of electricity production technologies in terms of sustainable development. Energy Conversion and Management, In press

[10] Shukla and Chaturvedi. 2012. Low carbon and clean energy scenarios for India: Analysis of targets approach. Energy Economics 34, S487-495

[11] William JH, DeBenedictis A, Ghanadan R, Mahone A, Moore J, Morrow III WR, Price S, Torn MS. 2012. The technology path to deep greenhouse gas emission cuts by 2050: The pivotal role of electricity. Science 335, 53

[12] Clarke L, Krey V, Weyant J, Chaturvedi V. 2012. Regional energy system variation in global models: Results from the Asian modeling exercise scenarios. Energy Economics 34, S293-S305

[13] GEA. 2012. Global Energy Assessment- Towards a sustainable future. Cambridge University Press, Cambridge UK and New York, NY, USA and the International Institute for Applied Systems Analysis, Laxenburg, Austria

[14] Doi N, Popov S, Barcelona E, Asano K. 2011. Assessment of investment requirement for low carbon power generation in Asia and the Pacific- cost of $\mathrm{CO} 2$ emission reduction and financial viability. Environmental Economics 2, 86-99

[15] WB. 2010. Lights out? The outlook for energy in Eastern Europe and the Former Soviet Union. The World Bank, Washington DC

[16] WEO. 2009. World Energy Outlook. International Energy Agency, Paris, France [17] WEO. 2010. World Energy Outlook. International Energy Agency, Paris, France 
[18] UNESCAP. 2008. Energy security and sustainable development in Asia and the Pacific. United Nations Economic and Social Commission for Asia and the Pacific

[19] Frankfurt School-UNEP. 2012. Global trends in renewable energy investment. Frankfurt School and UNEP Collaborating Centre for Climate and Sustainable Energy Finance

[20] UNFCCC. 2007. Investment and financial flows: To address climate change. United Nations Framework Convention on Climate Change. [20] OECD. 2006. Infrastructure to 2030: Telecom, Land Transport, Water and Electricity. Organization for Economic Cooperation and Development.

[21] IEA. 2003. World energy investment outlook: 2004 insights. International Energy Agency, Paris, France

[22] McCollum D, Nagai Y, Riahi K, Marangoni G, Calvin K, Pietzcker R, van Vliet J, van der Zwaan B. 2014. Investment, offsets, and incentives: an analysis of the $2^{\circ} \mathrm{C}$ target and what it takes to achieve it. Climate Change Economics, Accepted

[23] Carraro C, Favero A, and Massetti E. 2012. Investment and public finance in a green, low carbon, economy. Energy Economics 34, S15-S28

[24] Calvin K, Edmonds J, Bond-Lamberty B, Clarke L, Kim SH, Kyle P, Smith SJ, Thomson A, Wise M. 2009. 2.6: Limiting climate change to $450 \mathrm{ppm} \mathrm{CO2} \mathrm{equivalent} \mathrm{in} \mathrm{the} \mathrm{21st} \mathrm{century.} \mathrm{Energy}$ Economics 31, S107-S120

[25] Wise MA, Calvin KV, Thomson AM, Clarke LE, Bond-Lamberty B, Sands RD, Smith SJ, Janetos AJ and Edmonds JA. 2009. The implications of limiting CO2 concentrations for land use and energy. Science 324, 1183

[26] Wise MA, GP Kyle, JJ Dooley, SH Kim. 2010. "The Impact of Electric Passenger Transport Technology under an Economy-Wide Climate Policy in the United States: Carbon Dioxide Emissions, Coal Use, and Carbon Dioxide Capture and Storage." International Journal of Greenhouse Gas Control 4, 301-308

[27] Edmonds J, Calvin K, Clarke L, Kyle P and Wise M. 2012. Energy and technology lessons since Rio. Energy Economics 34, S7-S14

[28] Kyle, P and Kim, SH. 2011. Long Term Implications Of Alternative Light Duty Vehicle Technologies For Global Greenhouse Gas Emissions And Primary Energy Demands. Energy Policy 39, 3012-3024

[29] Eom J, Clarke L, Kim S, Kyle P, Patel P. 2012. China's building energy demand: Long term implications from a detailed assessment. Energy 46, pp. 405-419

[30] Chaturvedi V, Eom J, Clarke L, Shukla PR. 2014. Long term building energy demand for India: Disaggregating end use energy services in an integrated assessment modeling framework. Energy Policy 64, 226-242 
[31] Calvin K, Wise M, Kyle P, Patel P, Clarke L, Edmonds J. 2013. The effect of land and bioenergy policy on the path to achieving climate targets. Submitted to Climatic Change, Special Issue on EMF 27.

[32] Clarke L, Edmonds J, Jacoby HD, Pitcher HM, Reilly JM, Richels RG. 2007. Scenarios of greenhouse gas emissions and atmospheric concentrations. US Climate Change Science Program, Synthesis and Assessment Product 2.1a

[33] Thomson, Allison M., Katherine V. Calvin, Steven J. Smith, G. Page Kyle, April Volke, Pralit Patel, Sabrina Delgado-Arias, Ben Bond-Lamberty, Marshall A. Wise, Leon E. Clarke and James A. Edmonds. 2011. "RCP 4.5: A Pathway for Stabilization of Radiative Forcing by 2100," Climatic Change, Special Issue on Representative Concentration Pathways. 109:77-94. DOI 10.1007/s10584-011-0151-4.

[34] Clarke, L., Wise, M. Edmonds, J., Placet, M., Kyle, P., Calvin, K., Kim, S., Smith, S. 2008. CO2 Emissions Mitigation and Technological Advance: An Updated Analysis of Advanced Technology Scenarios. Pacific Northwest National Laboratory Technical Report PNNL-18075; U.S. Department of Energy: Richland, WA, USA.

[35] Chaturvedi V, Hejazi M, Edmonds J, Clarke L, Kyle P, Davies E, Wise M. 2013. Climate mitigation policy implications for global irrigation water demand. Mitigation and Adaptation Strategies for Global Change, In Press

[36] Kriegler E, Weyant JP, Blanford GJ, Krey V, Clarke L, Edmonds J, Fawcett A, Luderer G, Riahi K, Richels R, Rose SK, Tavoni M, van Vuuren DP. 2014. The role of technology for achieving climate policy objectives: overview of the EMF27 study on global technology and climate policy strategies. Climatic Change, DOI 10.1007/s10584-013-0953-7

[37] EIA. 2008. Annual Energy Outlook. Energy Information Agency, USA

[38] IEA. 2010a. Coal-Fired Power. IEA-ETSAP Technology Brief E01, April 2010

[39] IEA. 2010b. Gas-Fired Power. IEA-ETSAP Technology Brief E02, April 2010

[40] IEA. 2010c. Nuclear Power. IEA-ETSAP Technology Brief E03, April 2010

[41] IEA. 2010d. Biomass for Heat and Power. IEA-ETSAP Technology Brief E05, May 2010

[42] NREL. 2010. Energy Technology Cost and Performance Data. Accessed at http://www.nrel.gov/analysis/capfactor.html

[43] NASA. 2008. Surface meteorology and Solar Energy (SSE) Release 6.0 Data Set (Jan 2008)

[44] Jones S and Price H. 2003. Application of the systems-driven approach to solar trough and tower technologies.http://photovoltaics.sandia.gov/docs/PDF/Symposium2003/JonesandPrice.pdf

[45] EIA. 2013. Annual Energy Outlook. Energy Information Agency, USA

[46] EIA. 2012. Annual Energy Outlook. Energy Information Agency, USA 
[47] Kaya Y. 1990. Impact of carbon dioxide emission control on GNP growth: Interpretation of proposed scenarios. Paper presented to the IPCC Energy and Industry subgroups, Responses strategies working group, Paris 
Figures (colored)

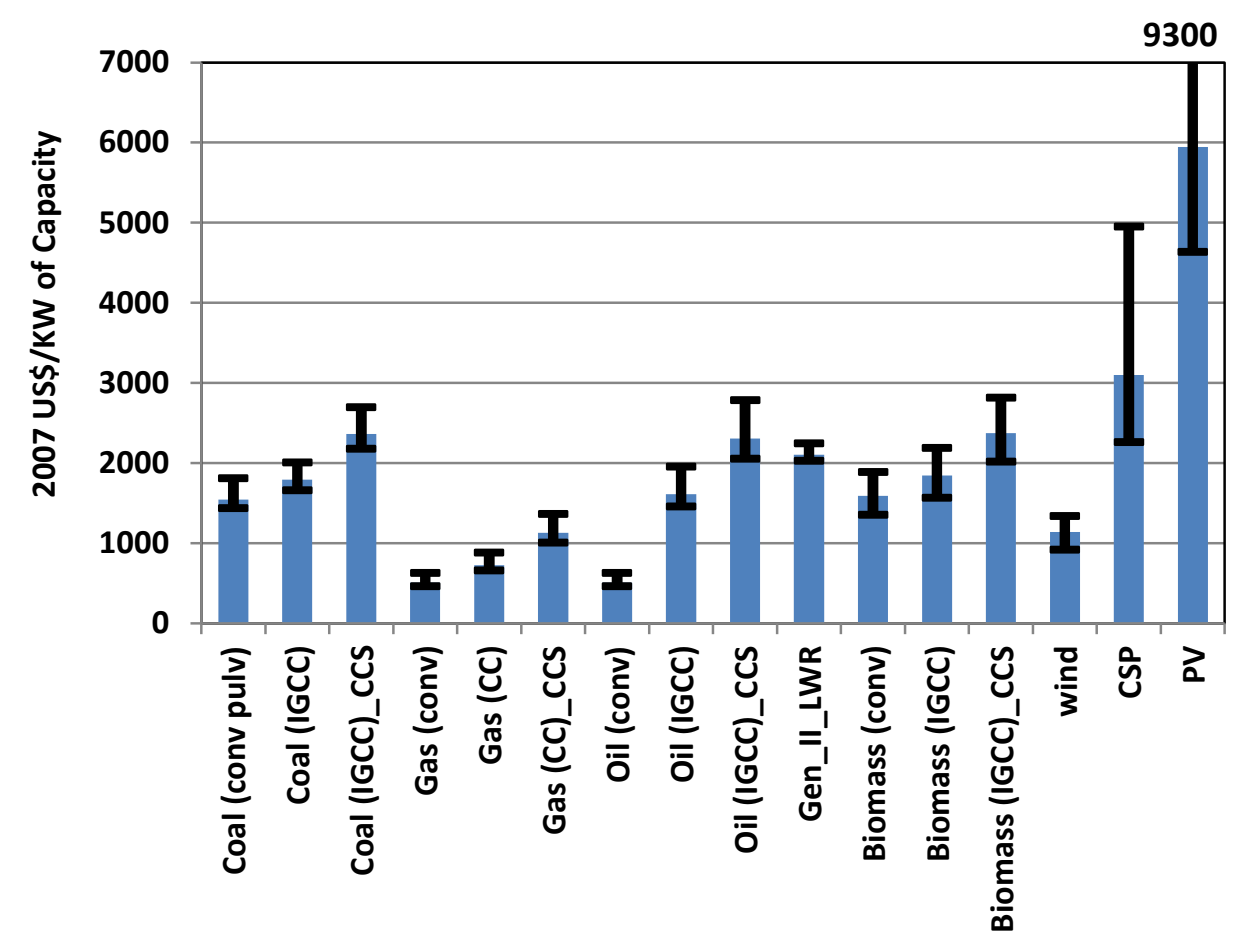

Figure 1: Capital cost assumptions and uncertainty range around it for 2020 


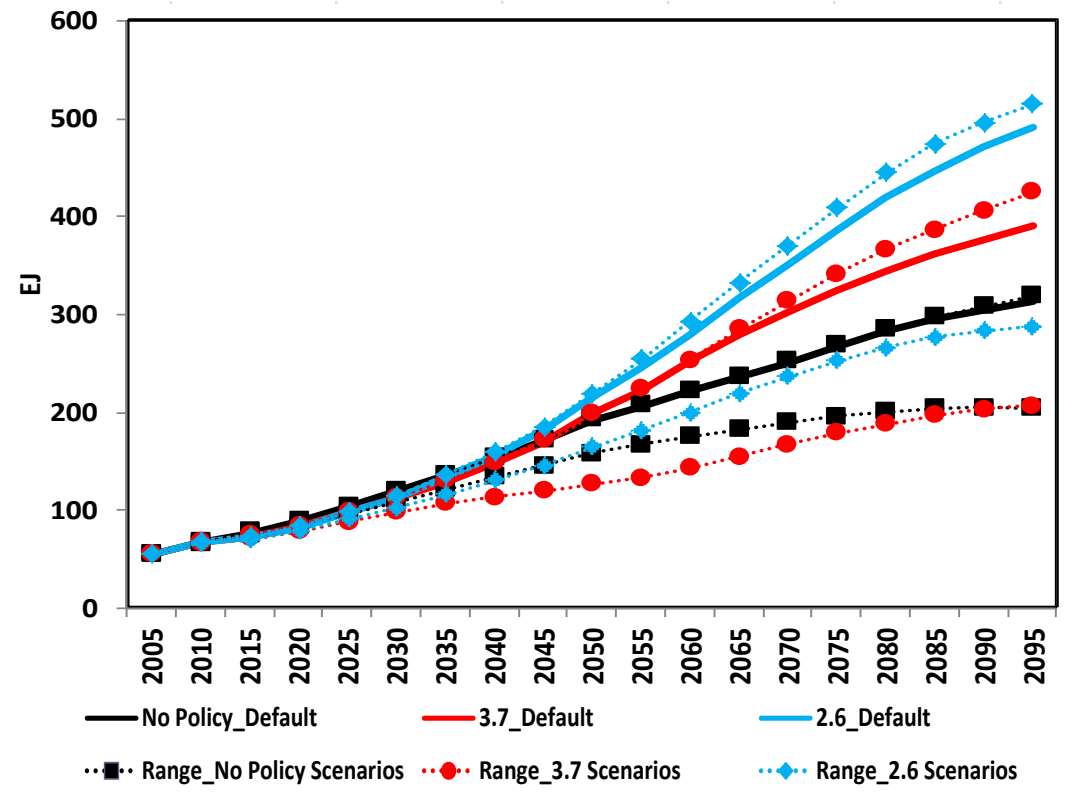

Figure 2: Electricity generation under different scenarios 


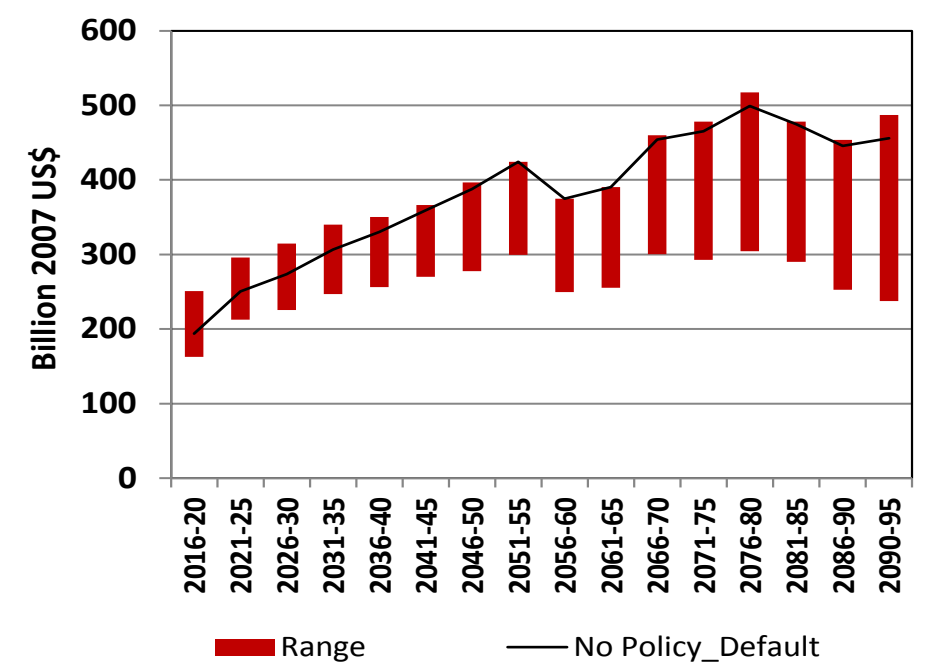

Figure 3: Global electricity generation investment under No Climate Policy scenarios 


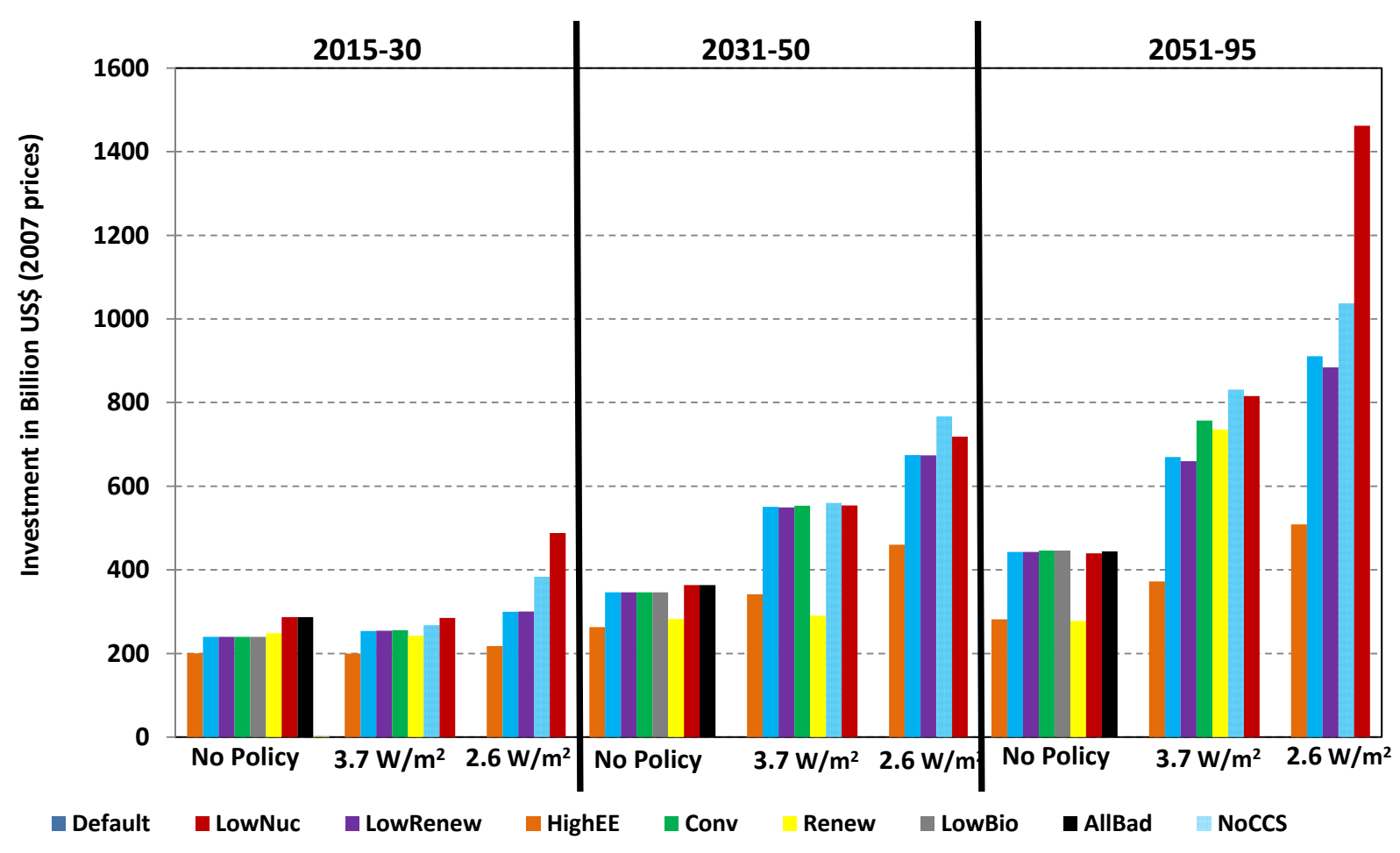

Figure 4: Average yearly investment in electricity generation by policy and technology scenario in different time periods (excludes investment transmission and distribution) Note: Different bars represent different technology scenarios under a given climate policy 


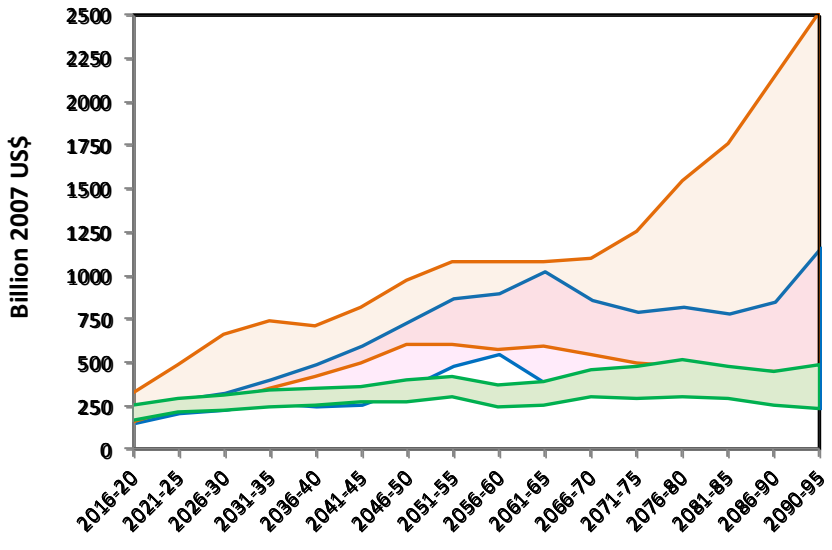

$\square$ No Climate Policy

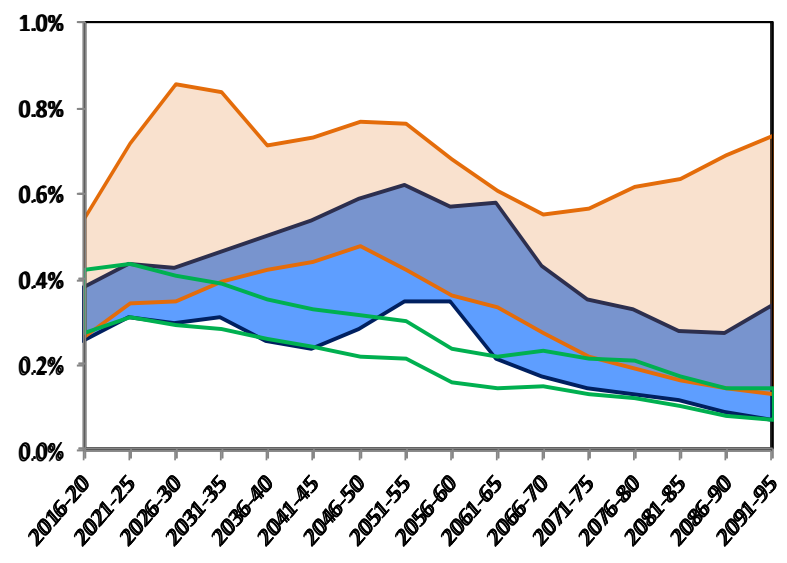

$2.6 \mathrm{~W} / \mathrm{m} 2$

Figure 5 : Range of electricity generation investment as a percentage of global GDP under different policy scenarios 


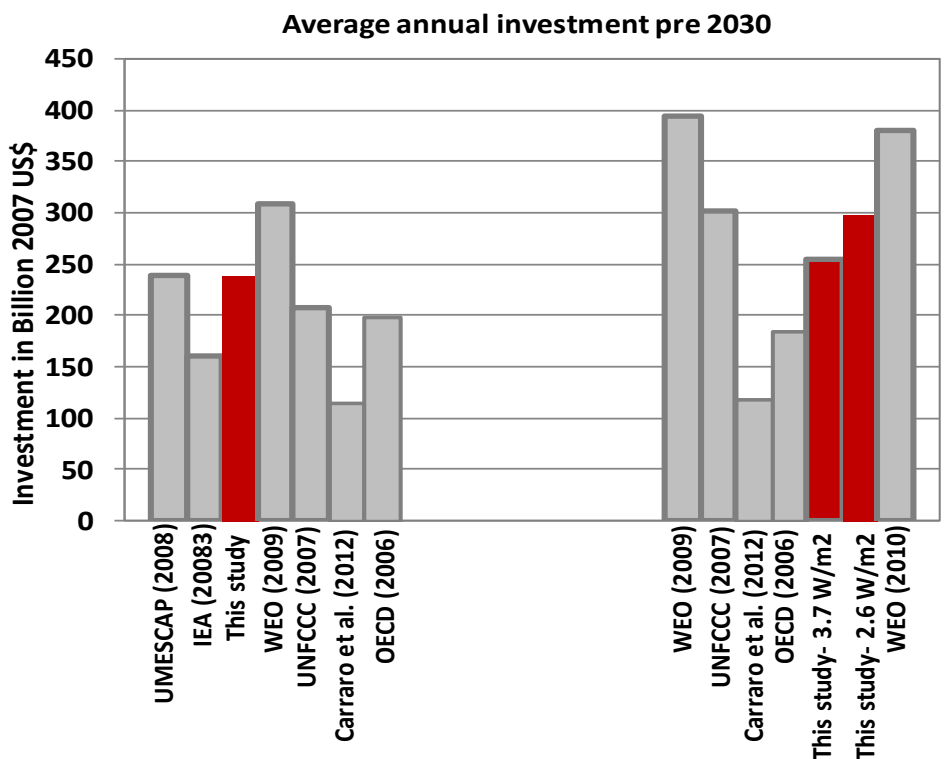

Note: WEO investments are pre 2035, Investment numbers for Carraro et al. have been derived from graphs in the paper, price year is not clear. Please note that time periods for the studies are different. Please refer

Table 1 for details regarding each study.

Figure 6: Comparison of investment estimates across studies 

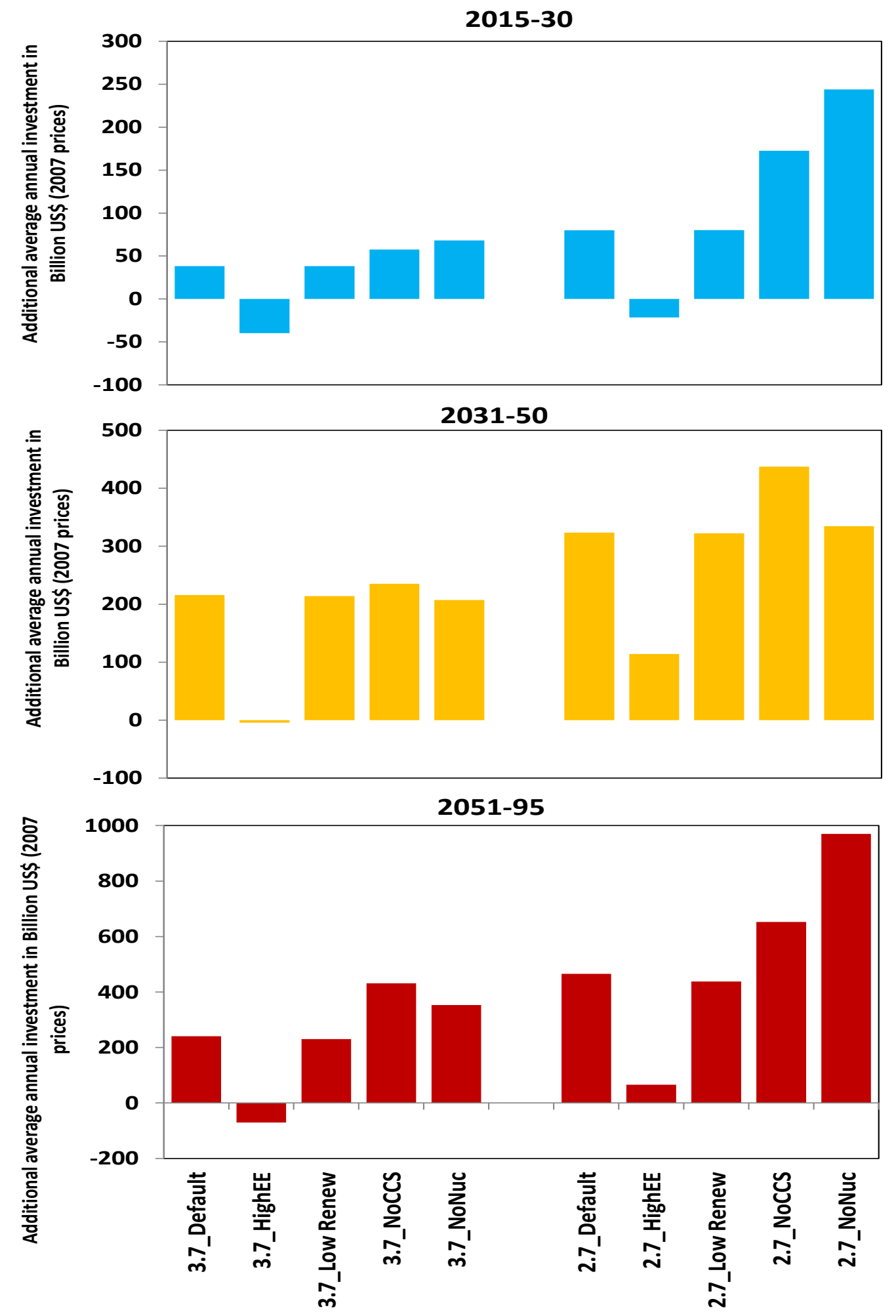

Figure 7: Additional electricity generation investments for specific technology scenarios compared to No Policy_Default scenario 


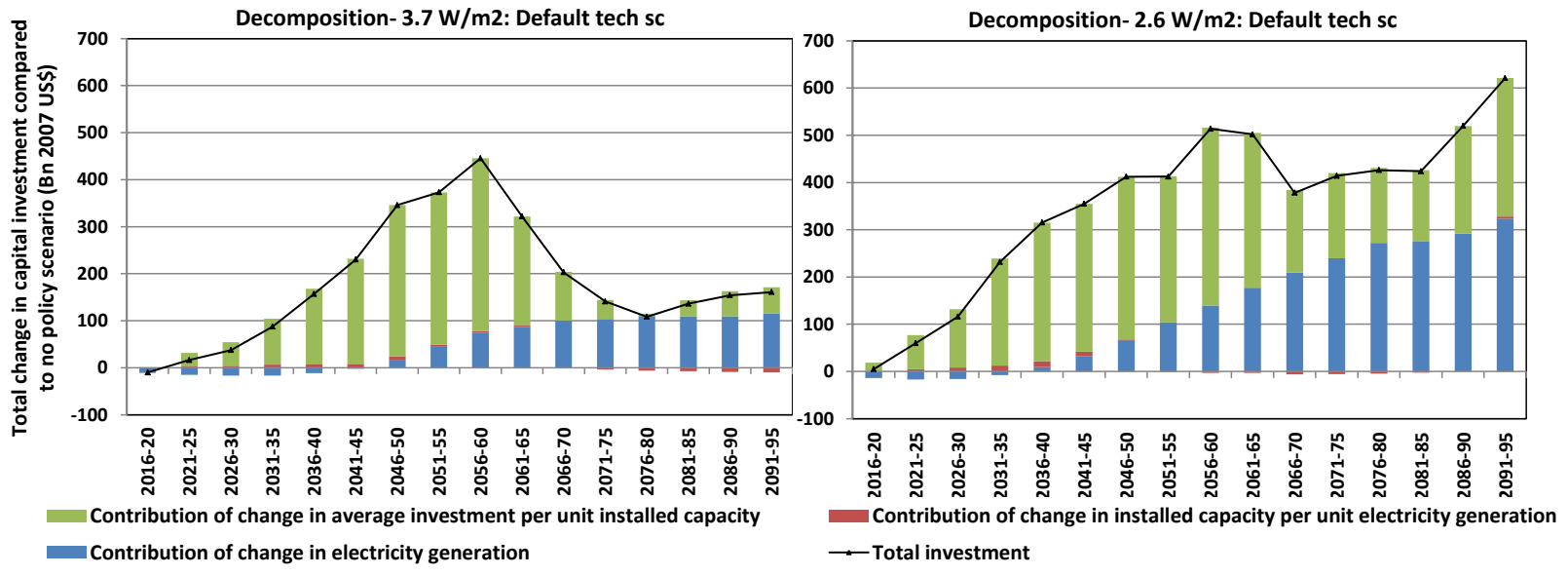

Figure 8: Decomposition of total change in capital investment, default technology scenarios 


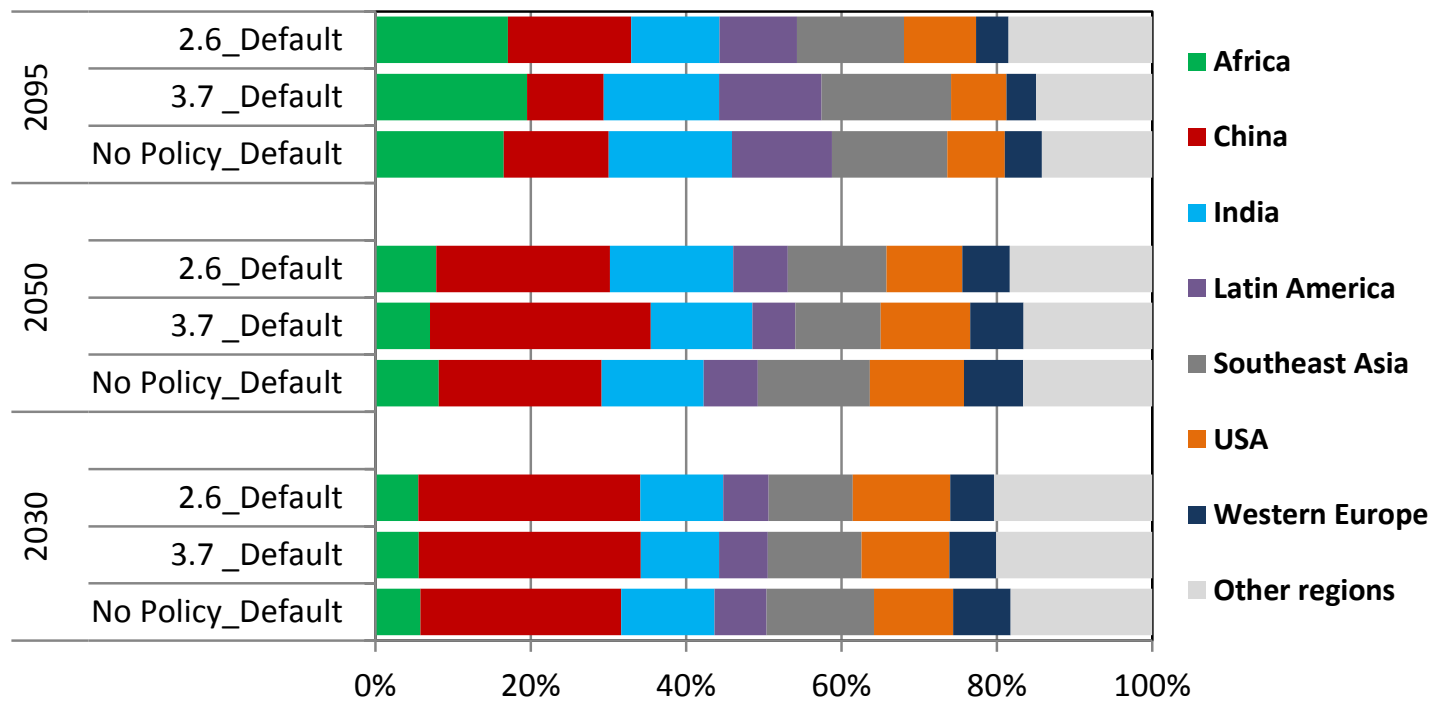

Figure 9: Share of different regions in global electricity investment across default technology scenarios 


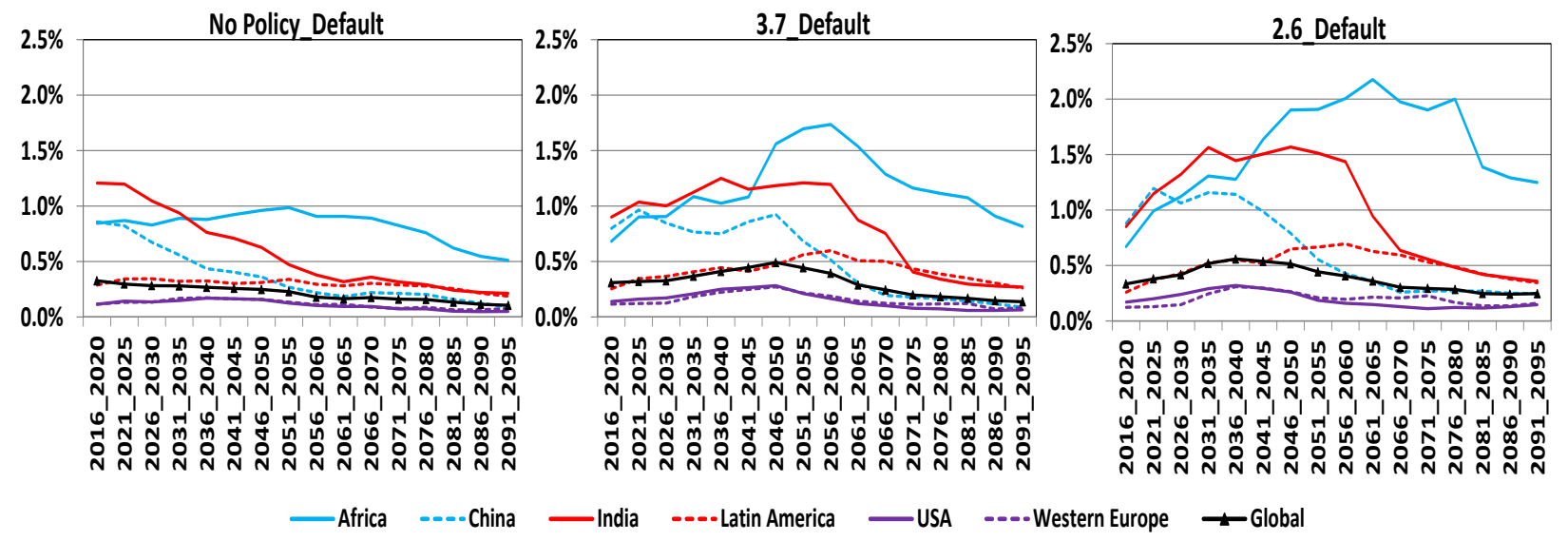

Figure 10: Investment requirement as a share of GDP under the default technology scenarios 


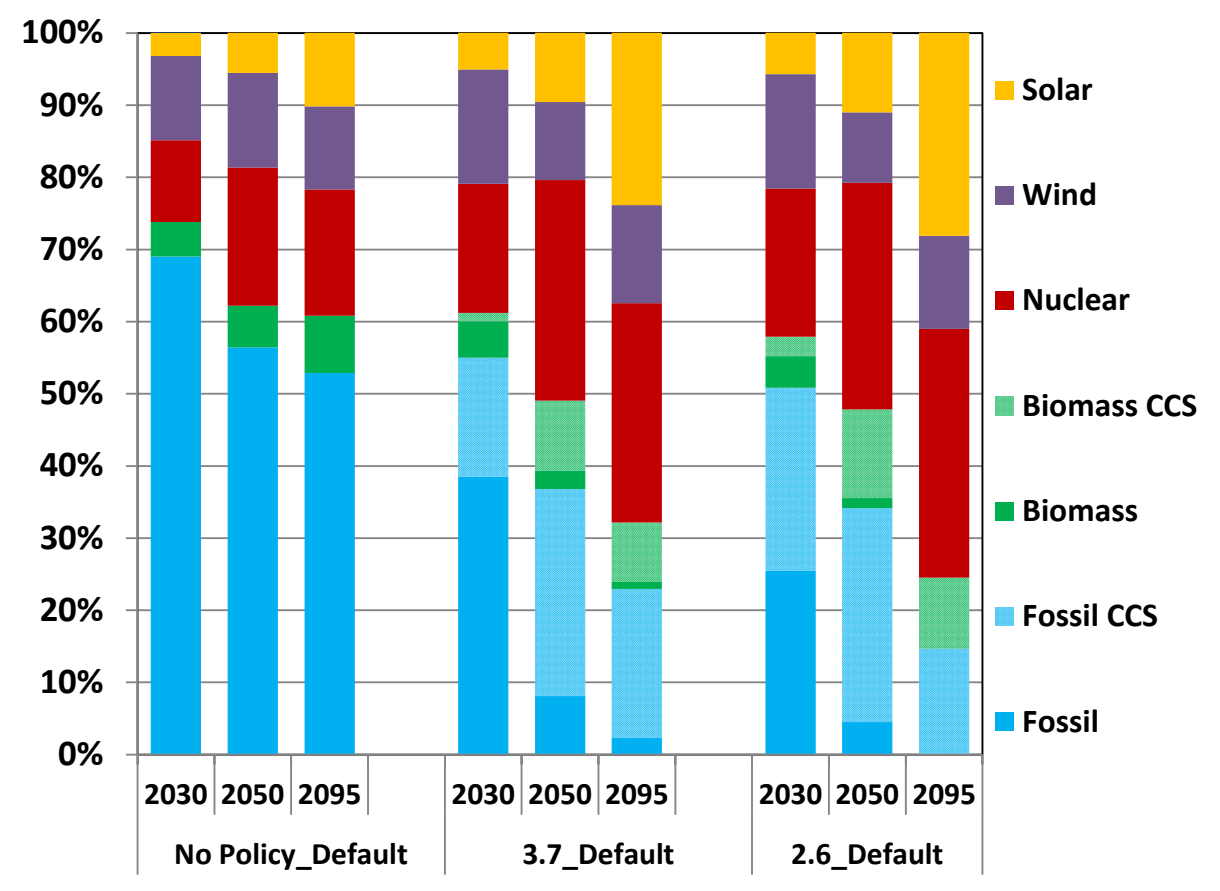

Figure 11: Share of investment by electricity generation technologies across default tech scenarios 


\section{Tables}

Table 1: Scenario description

\begin{tabular}{|c|c|c|c|c|c|c|}
\hline \multirow{2}{*}{ Scenario Name } & \multicolumn{5}{|c|}{ Technology characteristics } & \multirow{2}{*}{$\begin{array}{l}\text { Climate policy } \\
\text { characteristic }\end{array}$} \\
\hline & $\begin{array}{l}\text { Energy } \\
\text { intensity }\end{array}$ & $\operatorname{ccs}^{*}$ & $\begin{array}{l}\text { Nuclear } \\
\text { energy }\end{array}$ & $\begin{array}{l}\text { Wind } \\
\text { and solar }\end{array}$ & $\begin{array}{l}\text { Bioenergy } \\
\text { potential }\end{array}$ & \\
\hline No Policy_Default & Ref & On & On & Adv & High & No Climate Policy \\
\hline No Policy_HighEE & Low & On & On & Adv & High & No Climate Policy \\
\hline No Policy_LowNuc & Ref & On & Off & Adv & High & No Climate Policy \\
\hline No Policy_LowRenew & Ref & On & On & Cons & High & No Climate Policy \\
\hline No Policy_LowBio & Ref & On & On & Adv & Low & No Climate Policy \\
\hline No Policy_Conv & Ref & On & On & Cons & Low & No Climate Policy \\
\hline No Policy_Renew & Low & Off & Off & Adv & High & No Climate Policy \\
\hline No Policy_AllBad & Ref & Off & Off & Cons & Low & No Climate Policy \\
\hline 3.7_Default & Ref & On & On & Adv & High & $3.7 \mathrm{~W} / \mathrm{m}^{2}$ \\
\hline 3.7_HighEE & Low & On & On & Adv & High & $3.7 \mathrm{~W} / \mathrm{m}^{2}$ \\
\hline 3.7_NoCCS & Ref & Off & On & Adv & High & $3.7 \mathrm{~W} / \mathrm{m}^{2}$ \\
\hline 3.7_LowNuc & Ref & On & Off & Adv & High & $3.7 \mathrm{~W} / \mathrm{m}^{2}$ \\
\hline 3.7_LowRenew & Ref & On & On & Cons & High & $3.7 \mathrm{~W} / \mathrm{m}^{2}$ \\
\hline 3.7_Conv & Ref & On & On & Cons & Low & $3.7 \mathrm{~W} / \mathrm{m}^{2}$ \\
\hline 3.7_Renew & Low & Off & Off & Adv & High & $3.7 \mathrm{~W} / \mathrm{m}^{2}$ \\
\hline 2.6_Default & Ref & On & On & Adv & High & $2.6 \mathrm{~W} / \mathrm{m}^{2}$ overshoot \\
\hline 2.6_HighEE & Low & On & On & Adv & High & $2.6 \mathrm{~W} / \mathrm{m}^{2}$ overshoot \\
\hline 2.6_NoCCS & Ref & Off & On & Adv & High & $2.6 \mathrm{~W} / \mathrm{m}^{2}$ overshoot \\
\hline 2.6_LowNuc & Ref & On & Off & Adv & High & $2.6 \mathrm{~W} / \mathrm{m}^{2}$ overshoot \\
\hline 2.6_LowRenew & Ref & On & On & Cons & High & $2.6 \mathrm{~W} / \mathrm{m}^{2}$ overshoot \\
\hline
\end{tabular}

Note: Ref = Reference; Adv = Advance; Cons = Conservative 
Table 2: Capital cost of electricity generation technologies (2007 \$/kW of Capacity)

\begin{tabular}{|c|c|c|c|c|c|c|}
\hline & 2020 & 2035 & 2050 & 2065 & 2080 & 2095 \\
\hline Coal: Conv/Cogen & I,545 & I,455 & 1,370 & 1,290 & 1,215 & $\mathrm{I}, \mathrm{I} 44$ \\
\hline Coal: IGCC & I,79| & 1,610 & $|, 36|$ & 1,350 & 1,278 & 1,253 \\
\hline Gas: Conv/Cogen & 509 & 479 & 451 & 425 & 400 & 377 \\
\hline Gas: CC & 725 & 632 & 551 & 539 & 516 & 508 \\
\hline Oil: Conv/Cogen & 509 & 479 & 451 & 425 & 400 & 377 \\
\hline Oil: IGCC & 1,612 & $\mathrm{I}, 404$ & 1,225 & 1,196 & $\mathrm{I}, 145$ & 1,128 \\
\hline Biomass: Conv/Cogen & $|, 59|$ & $\mathrm{I}, 498$ & $I, 4 I I$ & 1,329 & $|, 25|$ & $\mathrm{I}, 178$ \\
\hline Biomass: IGCC & $\mathrm{I}, 844$ & 1,659 & $\mathrm{I}, 402$ & 1,390 & 1,316 & $|, 29|$ \\
\hline Nuclear: Gen II and III & 2,104 & 2,069 & 2,038 & 2,007 & $1,98 \mid$ & $|, 95|$ \\
\hline Wind & $\mathrm{I}, \mathrm{I} 40$ & 1,098 & $\mathrm{I}, 058$ & 1,019 & 981 & 945 \\
\hline Wind_storage & 2,575 & 2,380 & 2,247 & 2,164 & 2,084 & 2,007 \\
\hline CSP & 3,100 & 2,875 & 2,667 & 2,474 & 2,294 & 2,128 \\
\hline CSP_storage & 6,199 & 5,750 & 5,334 & 4,947 & 4,589 & 4,257 \\
\hline PV & 5,945 & 4,064 & 2,999 & 2,388 & 2,051 & 1,900 \\
\hline PV_storage & 7,380 & 5,346 & 4,188 & 3,533 & 3,154 & 2,962 \\
\hline Coal: IGCC_CCS & 2,361 & 2,074 & I,737 & 1,713 & 1,625 & I,595 \\
\hline Gas: CC_CCS & $\mathrm{I}, 127$ & 976 & 851 & 824 & 790 & 778 \\
\hline Oil: IGCC_CCS & 2,307 & 1,997 & 1,739 & $|, 69|$ & 1,622 & 1,599 \\
\hline Biomass: IGCC_CCS & 2,375 & 2,096 & 1,760 & $\mathrm{I}, 737$ & 1,648 & 1,618 \\
\hline
\end{tabular}

Note: Please note that technology costs have been assumed to be homogenous across GCAM regions. We thank the anonymous reviewer for highlighting that the near term cost might not be homogenous across regions, though we believe that in the long term costs will converge across regions which is the basis of our assumption within GCAM, which is a long term model. Hydro power generation and geothermal investments are not included in our estimates. 
Table 3: Capacity factor of electricity generation technologies (2007 $\$ / \mathrm{kW}$ of Capacity)

\begin{tabular}{|c|c|}
\hline Technology & $\begin{array}{l}\text { Assumed capacity } \\
\text { factor }\end{array}$ \\
\hline Coal and biomass technologies including CCS & $80 \%$ \\
\hline Gas and oil technologies including CCS & $40 \%$ \\
\hline All nuclear technologies & $85 \%$ \\
\hline Wind and wind storage & $\begin{array}{l}\text { Increases from } 40 \% \text { in } \\
2005 \text { to } 50 \% \text { in } 2095\end{array}$ \\
\hline PV and PV storage: Former Soviet Union and Eastern Europe & $20 \%$ \\
\hline PV and PV storage: Canada and Western Europe & $21 \%$ \\
\hline PV and PV storage: Japan & $24 \%$ \\
\hline PV and PV storage: USA, China and Korea & $25 \%$ \\
\hline PV and PV storage: Australia_New Zealand & $29 \%$ \\
\hline PV and PV storage:India & $30 \%$ \\
\hline PV and PV storage: Latin America and Southeast Asia & $31 \%$ \\
\hline PV and PV storage: Africa and Middle East & $34 \%$ \\
\hline CSP: Former Soviet Union, Eastern Europe and Canada & $24 \%$ \\
\hline CSP: Western Europe & $25 \%$ \\
\hline CSP: Japan & $28 \%$ \\
\hline CSP: China & $29 \%$ \\
\hline CSP: Korea and USA & $30 \%$ \\
\hline CSP: Australia_NZ & $35 \%$ \\
\hline CSP: India, Latin America and Southeast Asia & $36 \%$ \\
\hline CSP: Middle East & $39 \%$ \\
\hline CSP: Africa & $40 \%$ \\
\hline CSP Storage: Former Soviet Union and Eastern Europe & $56 \%$ \\
\hline CSP Storage: Canada & $57 \%$ \\
\hline CSP Storage: Western Europe & $58 \%$ \\
\hline CSP Storage: Japan & $65 \%$ \\
\hline CSP Storage: China & $69 \%$ \\
\hline CSP Storage: Korea and USA & $70 \%$ \\
\hline CSP Storage: Australia_NZ & $81 \%$ \\
\hline CSP Storage: India & $84 \%$ \\
\hline CSP Storage: Latin America and Southeast Asia & $85 \%$ \\
\hline CSP Storage: Africa and Middle East & $93 \%$ \\
\hline
\end{tabular}

Sources: Fossil, biomass, and nuclear technology capacity factors are based on IEA-ETSAP technology briefs [38], [39], [40], [41]. Wind capacity factor is based on [42]. Solar capacity factors are based on [37], [43]for solar irradiance values for different regions, and [44].

Note: Gas and oil based capacities have been given a lower capacity factors as these are used mainly for intermediate and peak power generation. Average capacity factors might change in the future with changing distribution of gas and oil based power generation between base load and intermediate and peak power generation, however we assume that the future distribution 
will not be significantly different from what is currently observed and hence should not affect our results. Solar capacity factors vary across regions based on the solar irradiance of different regions. Variation in wind capacity over time is based on [42]. 